\title{
Medical Professionals' Perspective on Virtual Autopsy: Comprehensive Analysis and Validation Study with Respect to Traditional Autopsy
}

\author{
Mohd Asrarul Haque \\ Assistant Professor, Department of Forensic Medicine, Jawaharlal Nehru Medical College, AMU, Aligarh (UP), \\ India
}

\begin{abstract}
Virtual autopsy is a specialized technique of postmortem examination where in radiological imaging techniques are used to scan body of dead to make opinion regarding cause of death and other valuables. It is performed independently or with traditional autopsy. There are numerous advantages of this technique over traditional autopsy. Due to technical and organizational problem, virtual autopsy service is not commonly in use in developing countries. In our study we have collected responses of medical professionals through questionnaires based on virtual autopsy facts, techniques, advantage, and disadvantage in comparison to traditional autopsy (TA). Results are heartening to know that most of the participants are well aware of the fact of our study objectives but more awareness is needed to promote this important aspect of medicolegal and forensic medicine practice to minimize time, energy and risk due to COVID 19 pandemic and other factors.
\end{abstract}

Key words: Autopsy, Virtual Autopsy, Traditional Autopsy, Postmortem examination, COVID 19 pandemic, ICMR, Non invasive autopsy, minimally invasive autopsy, Forensic Radiology

\section{Introduction}

An autopsy is a scientific procedure in which detail examinations of remains of deceased is being done to find out cause of death, time since death and to establish identity ${ }^{1}$. Autopsy is also known as necropsy or postmortem examination and is admired as the fundamental competence in forensic and medicolegal setting ${ }^{2}$.

Traditional postmortem procedure is dissection of dead bodies, opening of cavities, documentation and interpretation of findings, and record keeping ${ }^{3}$. Based on the findings, doctors give opinion regarding the case. The body of deceased is then given to relatives

\section{Corresponding author}

Dr Mohd Asrarul Haque

Mobile No.: 8755198534,

Email id: asrar2km@gmail.com for funeral purposes. In case if second autopsy is needed to verify previous findings or to examine more, it becomes very difficult and many times which is not possible 4 . Mutilation and disfigurement of dead body after traditional autopsy, makes the aggrieved family more sad and disturbed. Due to which, hostile attitude develops in the family members of dead and become sentimental of the fact and refuse further ${ }^{5}$. Our Indian society and cultural practices don't accept traditional autopsy practices completely and also many religious groups didn't consent for traditional autopsy ${ }^{6}$, though it is vital for medicolegal purpose, for criminal matter and civil dispute ${ }^{7}$.

Due to these limitations and evolution of technology in medical sciences, there was need of some advanced form of specialized autopsy procedure. This led to the genesis of virtual autopsy. Virtual and autopsy combines to form the word 'virtopsy'. 
'Virtospy' is term formed from the two independent words 'virtual' and 'autopsy'8. Techniques of radiological scanning are utilized for this purpose. It is a procedure to convert low technological documentation of facts and poor, lengthy, traditional; and traditional autopsy procedures to modern digitalized one in order to raise its scientific value, minimize subjective error and enhance importance and dignity of forensic medicine specialty ${ }^{9}$.

Virtual is related to Latin word 'virtus', meaning of which is 'useful, efficient and good'. Autopsy is a combination of two old Greek terms 'autos' (=self) and 'opsomei' (=I will see). So, virtual autopsy is a useful, efficient and good method of examination of dead body to investigate cause of death and to carry out research in the field of forensic medicine and pathology.

The aim of virtual autopsy is to remove the subjectivity of self visualization which is characteristics of traditional autopsy because in traditional autopsy, the appreciation of findings is to be done by the doctor while in virtual autopsy radiological imaging instruments play major role and only interpretation is in the part of doctor. Virtual Autopsy provides an opportunity for multidisciplinary scientific innovation and research involving Forensic Medicine, Pathology, Imageology, Biophysics, Radiology and Biomechanics ${ }^{\mathbf{8}}$.

Virtual autopsy is a highly specialized surgical procedure which can be employed as an alternative to standard autopsies for broad and systemic examination of the whole body as it is less time consuming, and aids better diagnosis ${ }^{10}$.

Virtopsy has numerous advantages with respect to traditional autopsy. There are certain limitations ${ }^{\mathbf{1 1}}$. Personnel handling virtual autopsy should be skilled in interpretation of imaging technology 9 .

Recently virtual autopsy project started in India for the first time by joint efforts of ICMR and AIIMS, New Delhir ${ }^{\mathbf{1 2}}$. This is the mile stone in popularizing this important aspect of forensic investigation to keep pace with technological advancement and digitalization globally.

Virtual autopsy procedure doesn't destroy integrity of the body of deceased and keep it intact. This is an attempt for dignified management of dead body ${ }^{13}$.

COVID-19 positive cases died due to unnatural and suspicious condition, indication for postmortem examination to investigate for solving allegations and give opinion with regards to cause, manner and mode of death. But due to the strong infectivity of COVID-19 and lack of experience of performing an autopsy in infectious disease-induced death, the pandemic created some challenges for forensic practitioners ${ }^{14}$. There is high risk of contracting infections if not proper safety precaution has taken like wearing mask, using sanitizer, using PPE Kit etc. ICMR guidelines recommend waiving of unnecessary autopsy, switching to non invasive techniques like digital and virtual autopsy and if much needed minimally invasive procedure can be employed $^{\mathbf{1 5}}$.

In this article, we have studied response of medical professionals regarding understanding of autopsy, indication of postmortem examination, advantage and disadvantage of traditional and virtual autopsy and comparative analysis, tackling of autopsy in case of death due to potentially infective condition like COVID 19. Hostility of relatives and loved once due to pitfalls of traditional autopsy. Ethical issues and limitations of virtual autopsy practice with reference to Indian setting. This article also highlights experience of how we handle the confirmed or suspected infectious cases and give some perspectives for the future in reference to virtual autopsy.

\section{Material Method}

Cross-sectional study was conducted to know the knowledge and different aspects of virtual autopsy through questionnaire based responses from medical professionals belonging to different colleges, hospitals and health care organizations in India.

A questionnaire was prepared by the author with multiple questions relevant to this study. Randomly 
sent to 250 study participants belonging to different institutions throughout India and their responses were noted. Inclusion criteria include medical professionals who have work experience in mortuary and performed or observed postmortem examination. Those who are not from medical background were excluded from study.

\section{Results}

Total study participants were $250(\mathrm{n}=250)$. Among them 137 were specialist medical doctors while remaining are MBBS doctors working in government hospitals or in private setting. 89 participants were female and 161 male. 102 doctors who took part in the study are working in government set up , 83 in corporate hospitals while rest are doing self medical practice.

\begin{tabular}{|c|c|c|c|c|}
\hline \multicolumn{5}{|c|}{ Responses of participants in tabular form with questionnaire $(n=250)$} \\
\hline S. No. & Questionnaire / Statement & Yes & No & Don't Know \\
\hline 1 & Virtual Autopsy is a specialised technique of post-mortem examination & ${ }^{10} 2$ & 127 & 21 \\
\hline 2 & $\begin{array}{l}\text { Radiological Techniques like CT / MRI/ USG etic used to scan whole } \\
\text { body of dead body in Virtual Autopsy }\end{array}$ & 129 & 102 & 20 \\
\hline 3 & $\begin{array}{l}\text { Virtual Autopsy procedure is less time consuming then traditional } \\
\text { autopsy }\end{array}$ & 126 & 105 & 19 \\
\hline 4 & $\begin{array}{l}\text { Virtual Autopsy procedure prevents from exposure of infections to } \\
\text { medical personnel from body fluids in infective conditions like COVID } \\
19\end{array}$ & 126 & 102 & 22 \\
\hline 5 & $\begin{array}{l}\text { Virtual Autopsy more good in dealing with religious issues arises to do } \\
\text { traditional autopsy }\end{array}$ & 138 & 89 & 23 \\
\hline 6 & $\begin{array}{l}\text { Virtual Autopsy can be employed as an alternative to standard autopsies } \\
\text { for broad and systemic examination of the whole body }\end{array}$ & 128 & 100 & 22 \\
\hline 7 & Virtual Autopsy aids better diagnosis than conventional autopsy & 123 & 104 & 23 \\
\hline 8 & $\begin{array}{l}\text { Virtual Autopsy can be employed independently in forensic examination } \\
\text { of the dead or as an addition to conventional autopsy }\end{array}$ & 119 & 104 & 27 \\
\hline 9 & $\begin{array}{l}\text { Virtual Autopsy is especially useful in detecting smaller lesions as well } \\
\text { as lesions from areas that are difficult to approach by conventional } \\
\text { autopsy }\end{array}$ & 132 & 95 & 23 \\
\hline 10 & $\begin{array}{l}\text { Virtual Autopsy has a promising role in examination of burnt/charred } \\
\text { bodies where the fractures can be detected more easily than in the routine } \\
\text { autopsy }\end{array}$ & 121 & 108 & 21 \\
\hline 11 & $\begin{array}{l}\text { Virtual Autopsy contributes more in dignified management of dead body } \\
\text { as compared to traditional autopsy }\end{array}$ & 134 & 98 & 18 \\
\hline 12 & $\begin{array}{l}\text { Autopsy of COVID positive bodies made more importance of non } \\
\text { invasive autopsy techniques like Virtual Autopsy }\end{array}$ & 135 & 106 & 9 \\
\hline 13 & Virtual Autopsy is a non invasive autopsy method & 114 & 135 & 1 \\
\hline 14 & $\begin{array}{l}\text { Virtual Autopsy creates digital and permanent records of the body } \\
\text { making interpretation easier }\end{array}$ & 126 & 111 & 13 \\
\hline 15 & $\begin{array}{l}\text { Virtual Autopsy reports can be shared electronically among medical } \\
\text { professionals and experts and can be stored for future retrieval and re } \\
\text { examination }\end{array}$ & 113 & 128 & 9 \\
\hline 16 & $\begin{array}{l}\text { Virtual Autopsy technique is expensive and include high equipment and } \\
\text { technology cost }\end{array}$ & 152 & 90 & 8 \\
\hline
\end{tabular}

Regarding response on virtual autopsy which is a specialized technique about $69 \%$ gave positive response about it.

Radiological Techniques like CT / MRI/ USG/ postmortem CT angiography/ surface scanning etc are used to scan whole body of dead body in Virtual Autopsy is the basic need for performing this specialized procedure but out of 250 responses only 129 participants put positive response.

Virtual Autopsy procedure is less time consuming then traditional autopsy. Scanning takes less time than opening of body cavities, inspecting individual organs. 126 participating doctors understand this fact, 105 put negative response and 19 did not know about this. High 
training is needed to perform traditional autopsy in high infective cases like death due to COVID 19. There is risk of spillage of body fluid which is contagious. Antiseptic and full protective measures should be taken by the team in action. To avoid this various associations and health ministry of many countries recommended non invasive autopsy techniques like virtual autopsy. In our study 126 medical personnel knew this, 102 not while 22 did not know anything.

Cultural and religious practices disallow cutting of dead body which is mandatory in traditional autopsy (TA) practice. As virtual autopsy is a scanning technique, there is no invasiveness, no cutting, disfigurement or mutilation of deceased body. There is no objection or hostility among relatives or loved once due to religious issues. As per response received, out of 250 participants 138 were familiar with this, 89 not and 23 not knowing.

There is less discrepancies between findings of virtual autopsy and traditional autopsy. Technologically both are different. Virtual autopsy is best alternative of standard autopsy procedures for broad and systemic examination. This supported by views of our study participants where in 128 respond positively, 100 negative while 22 did not know about this issue.

Virtual autopsy gives better diagnosis than traditional autopsy. The areas in the body which are not approachable by routine traditional autopsy procedures can be scanned while doing virtual autopsy. Samples can be taken from least approachable area like spine using minimally invasive technique. Certainly these aid better diagnosis. The same thing is reflected in our study. 123 participants (49.2\%) supported this comparative study which is consistent with other studies conducted time to time.

Virtual autopsy is sufficient independently to give opinion regarding cause, manner, and mode of death. Sometimes it can be employed during conventional procedure to get samples from certain area of body which is out of approach in traditional method.

This fact also supported by the responses 119 $(47.6 \%)$ which we received from the study participants.

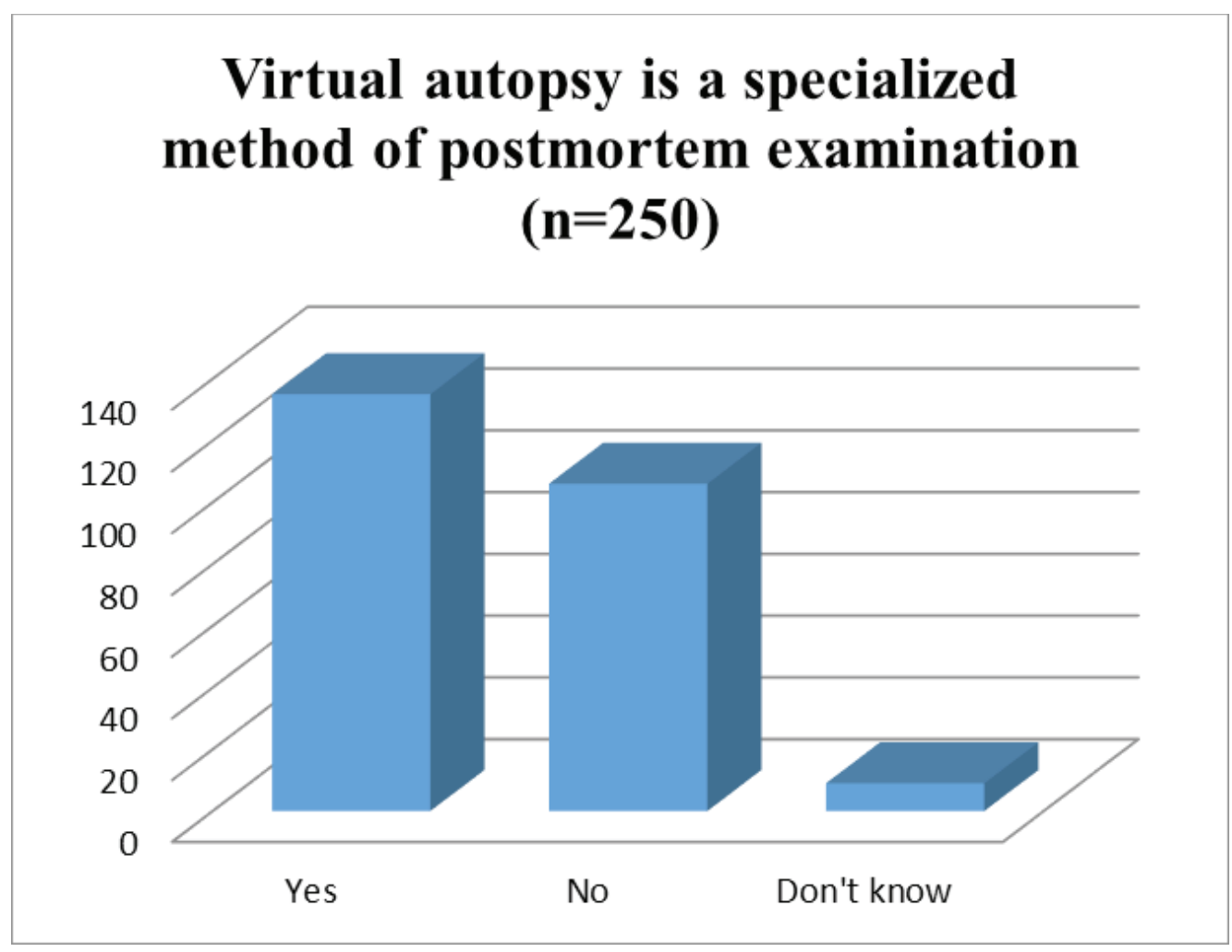

Figure 1. 
Autopsy on COVID 19 positive bodies made more importance of non invasive autopsy techniques like virtual autopsy $(n=250)$

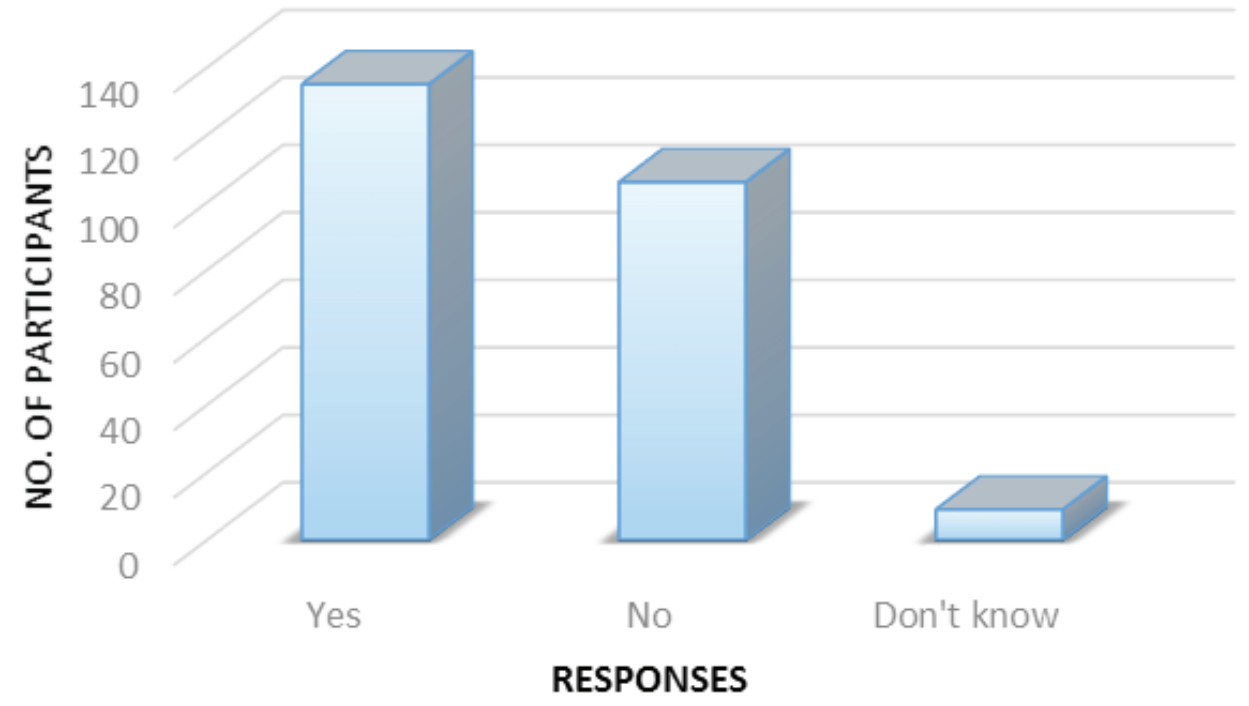

Figure 2.

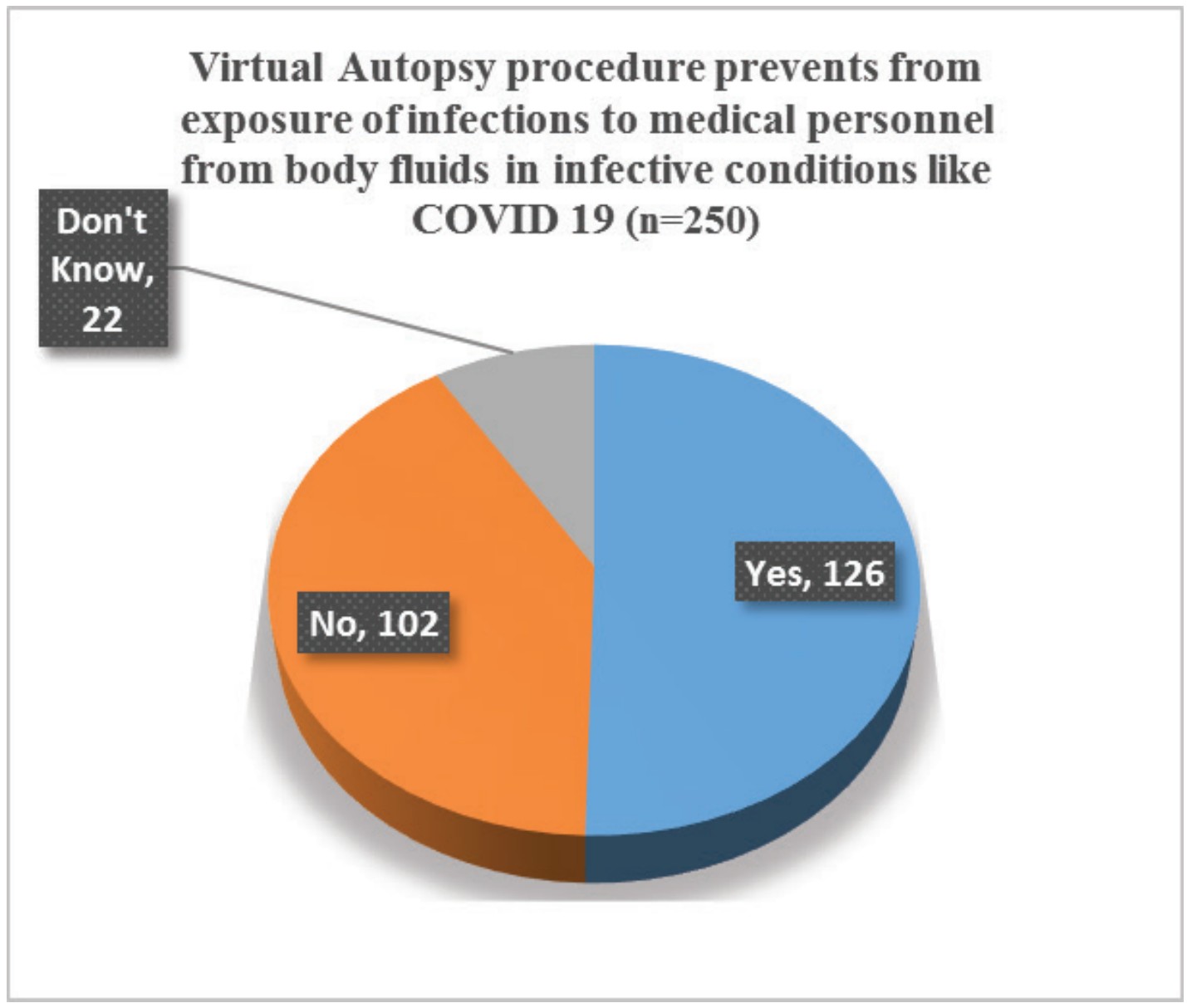

Figure 3. 
Whole body imaging in virtual autopsy is especially useful in detecting smaller lesions as well as lesions from areas that are difficult to approach by traditional autopsy. Likewise, the areas that are not examined routinely in traditional autopsy, such as the spine, pelvis, and the limbs, can also be examined in detail without any mutilation of the body. This fact was positively responded by $132(52.8 \%)$ participants.

Virtual autopsy is more reliable in diagnosing burnt and charred body and damaged oral cavity, localizing foreign body, identifying fracture lines, entry and exit wounds, pathological gas collections, and gross tissue injury, estimating the time of death, retinal hemorrhage, electric injury to the skin, and age and sex determination. This study objective is very important because of limitation of traditional autopsy in this valuable aspect. Out of 250 medical doctors who participated in this study, 121 (48.4\%) gave positive response of this fact.

Family member of the deceased feel uncomfortable with the traditional way of postmortem. They don't want an autopsy done. But they have no choice as postmortem is an important part of police investigation in case of unnatural death. Since virtual autopsy procedure is non invasive, no cutting of dead body. There is no deformity, mutilation of body. This practice contributes to dignified management of dead body. Among 250 Medical professionals $(\mathrm{n}=250)$ who participated in our study, 134 (53.6\%) were in the opinion that this modern virtual autopsy technique contributes to the dignified management of dead.

Virtual autopsy will be helpful in examining the infected bodies. This method reduces risk of infection to the operator autopsy technician and pathologist. This approach is very promising. We received responses from $135(54 \%)$ as yes, $106(42.4 \%)$ as no whereas $9(3.6 \%)$ as don't know.

Virtual autopsy is non invasive procedure as no cut is needed in this procedure. Dead body is scanned using radiation. $114(45.6 \%)$ participants responded positively with this questionnaire.
The images, findings, recordings from virtual autopsy are permanent, clear and digitalized. This is not same with traditional autopsy. Majority of study participants (126/50.4\%) supported this fact which is one of the very important advantages of virtual autopsy.

Stored data can be retrieved long after burial or cremation of corpse and can be transferred electronically thus allowing for a new assessment by different expert if need arises. In this study 113 (45.2\%) participants knew this fact, $128(51.2 \%)$ responded negatively, whereas 9 $(3.6 \%)$ were not knowing anything regarding this.

Virtual autopsy setup is costly. Organizational and technological arrangement needs high investment. There will be high equipment and technology cost. 152 (60.8\%) participants responded positively in this questionnaire.

\section{Discussions}

Medical professionals' perspective on autopsy procedures is crucial, because they are most often remain in contact with deceased and dying people; they deal with the family, friends and relatives of dying individual ${ }^{\mathbf{1 6}}$; and in Indian setting Registered Medical Practitioner is eligible to carry out death investigation and perform autopsy ${ }^{5}$.

Present research properly investigated and related medical professionals' perspectives on the practice and application of autopsy methods (virtual autopsy and traditional autopsy) for death investigation, in addition analyzed expected hurdles, advantage and needs of virtual autopsy enactment, to better recognize efficiency for their future use for forensic investigation.

Most of the findings regarding views on virtual autopsy among medical professionals are consistent with previous studies ${ }^{3,8,9,10,11,12,17 . ~}$

Autopsy of a loved one's is grief and emotional moment causes visual impact of deceased body, a factor identified in previous studies as a potential barrier for acceptability and feasibility ${ }^{17}$. Traditional autopsy needs complete dissection of organs after opening of body cavities. Integrity is lost. Body gets deformed and 
mutilated $^{5}$. This is the major reason of lakeside and hostile attitude Whereas Virtual autopsy procedure can be conducted in many ways. Means by which it can be carried out includes:

Non invasive

- Plain x-rays.

- CT scans with or without contrast.

· Magnetic Resonance Imaging.

- Ultrasound scans.

Minimally invasive

- Ultrasound-guided fine-needle biopsy e.g. of the liver.

Aspiration of pathological fluids such as pleural effusions.

All of these investigations would retain the bodily integrity of the deceased, satisfying cultural, religious and family requirements ${ }^{\mathbf{1 8}}$. That, in fact, is the primary reason for the increasing use of virtual autopsies internationally.

Autopsy findings and their interpretation in deaths due to infective conditions like COVID 19, AIDS, Hepatitis and other highly contagious diseases is of great significance in public health professionals to formulate guidelines for prevention and treatment of such diseases at community level. But the risk of spread of infection to the autopsy room staff including doctors and technicians in traditional autopsy compel the search of alternative autopsy technique which reduces, minimizes risk of contamination by infected body fluids which is potential source of infection and spread of infection. In such cases, various recommendations strongly suggest for opting virtual autopsy ${ }^{15,19}$.

As per perception of medical professionals in our study, risk of infection is minimum in virtual autopsy as this technique is non invasive or minimally invasive. It is similar to what was found in previous studies ${ }^{15,17,18}$, and 19 .
Owing to all the advantage and other benefits of virtual autopsy, there is joint effort of AIIMS , New Delhi and ICMR for developing Virtual Autopsy Centre in India ${ }^{\mathbf{1 2}}$.

Once incumbent Union Health Minister quoted saying India will be the first country in South and Southeast Asia to carry out these virtual autopsies. This will be the milestone in criminal investigation and it will contribute greatly in forensic medicine due to numerous advantages $^{20}$.

This research supported study objective as virtual autopsy is very important work and global studies on its applicability are tribute for dignified management of dead bodies ${ }^{\mathbf{1 3}}$.

Postmortem imaging is a good forensic visualization tool with a great potential for the forensic documentation and examination of charred bodies. Virtopsy has a promising role in examination of burnt/charred bodies where the fractures can be detected more easily than in the routine autopsy ${ }^{21,22}$.

Areas which are not routinely examined in traditional autopsy such as the spine, pelvis, and the limbs, can also be examined in detail without any mutilation of the body through radiological scanning in virtual autopsy ${ }^{22,23}$.

As in virtual autopsy, there is very accurate documentation, which depends on the applied resolution, can document structures less than $1 \mathrm{~mm}$ in size (smaller lesions) ${ }^{23}$.

A noteworthy advantage is that the images both radiological and histological could be retained indefinitely are available for re-evaluation and reinterpretation as for research and study purposes which can be used for future references as well as for an expert consultation at a later date ${ }^{18,22}$.

Investigations such as liver biopsy that had not been possible before death due to coagulation abnormality for example, would be feasible after death ${ }^{\mathbf{1 8}}$.

Potential barriers which came out of our study 
includes

- Costly operational work

- Inequitable distribution of resources between urban and rural setting

- Lack of expert and skilled professionals

- Difficult to appreciate changes in colour/texture/ consistency of organs and tissues

- Unable to comment on consistency of organs

- Inability to appreciate smell from body cavities

- Bioethical issue like confidentiality, privacy of images and data storage

- Judicial validity is under debate

These are hurdles in implementing virtual autopsy procedure and limit its use in Indian setting where inequitable distribution of resources and facilities are prevalent ${ }^{24}$.

As per the topic of our study, till now most of the facts are theoretical based but to carry out research to understand perceived limitations and to aware peoples of potential advantages, we need to have systematic approach to facilitate acceptability and applicability of virtual autopsy. Keeping this in mind, medical professionals took part in the study to analyze virtual autopsy by looking at it as a research and innovation. To examine issues addressed by this study, Diffusion of Innovations Theory (DOI) was used. To describe our findings on participants' responses on characteristics of innovation itself we studied factors which influence such as relative advantage, compatibility, complexity, triability and observability ${ }^{25}$. This study has shown that medical professionals, directly or indirectly, can act as strong supporter and critics of the virtual autopsies.

Foremost drawback of this study is that it was done to interpret a wider research question involving a broad range of target population, from which a small group of medical professionals' feedback was used for this research analysis. Being small sample, our findings lacks generalizability to whole target groups due to participation of only one sub group medical professionals. As ours a qualitative study, this may not represent perceptions of participants in other setting. Finally, Autopsy procedures which were discussed with study participants as hypothetical scenarios, and virtual autopsies is not in common practice yet, so it is essential to endorse these results under real situation to implement virtual autopsy practice.

\section{Conclusions}

In the light of participation of medical professionals in the study, the use of autopsy procedures is appropriate under standard guidelines and regulations. It is primary duty of autopsy surgeons to find out cause of death by performing postmortem examination.

Medical professionals commonly found the virtual autopsy more adequate and attainable than traditional autopsies. Virtual autopsy is seen less agreeably in contrast to the traditional autopsy only in terms of its perceived digital privacy issue and high costing, but it performs amicably when compared to the traditional autopsy for being less complex, less time consuming, not disfiguring and for posing less risk of infection among the performers. However, its modesty could be threatened by the alien behavior of leaders from community, no systematic death notification, gloomy perception of death occurrence, and unavailability of equipment and skilled manpower. Responses from participants could clearly reveal strengths and constraints of virtual autopsies, approving the trialability and observability of the virtual autopsy as likeliness for adoption of innovation.

Medical professionals constitute the most perceptive professionals to the technique of autopsy procedures, and may become key leader for future use of virtual autopsies in settings where more invasive methods such as the traditional autopsy would not be feasible. Nonetheless, it would be prime concern to reveal their feedback related to acknowledge technical errors and to secure all-inclusive training on necessary horizon for the practice of this innovative technique. 
Acknowledgement: The author wishes to acknowledge the assistance rendered by his students in searching literatures and relevant materials which helped conducting this study.

\section{Conflict of Interest -Nil}

\section{Source of Funding -Self}

Ethical Clearance - Obtained From Institutional Ethics Committee

\section{References}

1. Joseph TI, Girish KL, Sathyan P, Kiran, MS, Vidya S. Virtopsy: An integration of forensic science and imageology. J for dental sci 2017; 9(3):111-114.

2. Zacharias $\mathrm{M}$, Zacharias E. Dictionary of legal medicine. 2nd ed. Curitiba: University Publishing House, Champagnat; 1991

3. Lundberg GD. Low-tech autopsies in the era of high-tech medicine: Continued value for quality assurance and patient safety. JAMA 1998; 280:1273-4.

4. Menezes RG, Monteiro FN. Forensic Autopsy. StatPearls Publishing; 2021

5. Kotabagi, RB, Charati, SC, Jayachandar D. Clinical Autopsy vs Medicolegal Autopsy. Med J, Armed Forces India 2005; 61(3): 258-263.

6. Finkbeiner WE, Ursell PC, Davis RL, Connolly AJ. Legal, Social, and Ethical Issues. Autopsy Pathology 2009: 15-24.

7. Tamuli RP. Medicolegal Investigation of Medical Negligence in India: A Report of Forensic Autopsy Case. J Forensic Sci Med 2016; 2:167-70.

8. Thali MJ, Jackowski C, Oesterhelweg L, Ross SG.; Dirnhofer R. VIRTOPSY - The Swiss virtual autopsy approach. Legal Medicine 2007; 9 (2): 100-104.

9. Bolliger SA, Thali MJ. Imaging and virtual autopsy: looking back and forward. Phil. Trans. R. Soc. B 2015; 370 (1674): 20140253.

10. Tejaswi KB, Periya, HEA. Virtopsy (virtual autopsy): A new phase in forensic investigation. J forensic dental sci 2013; 5(2): 146-148.

11. Kumar R. Virtopsy complementing traditional autopsy. IP International Journal of Forensic Medicine and Toxicological Sciences 2020; 5(2) :
$39-42$.

12. Jha DN. Delhi: AIIMS set to start virtual autopsy, no cuts needed. The Times of India. Delhi News. Mar 20, 2021. https://timesofindia.indiatimes.com/ city/delhi/aiims-set-to-start-virtual-autopsy-nocuts-needed/articleshow/81595090.cms accessed on 23-05-2021

13. Pan American Health Organization. Management of Dead Bodies in Disaster Situations. https://www. who.int/hac/techguidance/management_of_dead bodies.pdf . accessed on 23 -05-2021

14. Lacy JM, Brooks EG, Akers J, Armstrong D, Decker L, Gonzalez A, Humphrey W, Mayer R, Miller M, Perez C, Arango JAR, Sathyavagiswaran L, Stroh W, Utley S. COVID-19: Postmortem Diagnostic and Biosafety Considerations. Am J Forensic Med Pathol. 2020 Sep; 41(3):143-151.

15. Standard guidelines for medico-legal autopsy in covid-19 deaths in India. https://eaaf.org/wpcontent/uploads/covid19-PDFs/India/COVID19 AUTOPSY_GUIDELINES_2020_10052020.pdf accessed on $23-05-2021$

16. Hadders H, Paulsen B, Fougner V. Relatives' participation at the time of death: Standardisation in pre and post-mortem care in a palliative medical unit. European Journal of Oncology Nursing 2014; 18 (2): 159-166.

17. Maixenchs M, Anselmo R, Sanz A, Castillo P, Macete E, Carrilho C. Healthcare providers' views and perceptions on post-mortem procedures for cause of death determination in Southern Mozambique. PLoS ONE 2018; 13(7): e0200058.

18. Tierney E, Ebrahim W, Baithun S, Corbally M, Albareeq J. Is It Time for a Virtual Autopsy Service in Bahrain? Bahrain Medical Bulletin, 2014. 36 (4)

19. Faculty of pathology Royal College of Physician of Ireland. Recommendations Relating to PostMortem Examination Practice during the Covid-19 Pandemic. https://rcpi-live-cdn.s3.amazonaws. com/wp-content/uploads/2020/05/Faculty-ofPathology-Autopsy-Guidelines-during-Covid-19Pandemic.pdf Accessed on 23-05-2021

20. https://www.virtualautopsy.co.uk/india-to-startvirtual-autopsy-soon-says-union-health-ministerdr-harshvardhan/ Accessed on 23-05-2021

21. Thali MJ, Yen K, Plattner T, Schweitzer W, Vock P, Ozdoba C, Dirnhofer R. Charred body: virtual autopsy with multi-slice computed tomography and 
magnetic resonance imaging. J Forensic Sci. 2002; 47(6):1326-31.

22. Kanchan T, Saraf A, Krishan K, Misra S. The advantages of virtopsy during the Covid-19 pandemic. Medico-Legal Journal 2020; 88(1_ suppl):55-56. doi:10.1177/0025817220943035

23. Aggarwal K, Chauhan A, Shukla SK. Implementation of Virtual Autopsy in Forensic Medicine. Indian J Forensic Med Tox. 2019; 13(2): 68-72.
24. Chandru K. Virtopsy: The Emerging Trend in Forensic Medicine. Indian J Forensic Med Tox 2019, Vol. 13, No. 3: 16-18.

25. Behavioral Change Model. https://sphweb.bumc. bu.edu/otlt/MPH-Modules/SB/Behavioral Change Theories/ Behavioral Change Theories4. html Accessed on 25-05-2021 